\title{
Giving In A Time Of Terrorism
}

Walter O. Simmons, John Carroll University, USA

Rosemarie Emanuele, Ursuline College, USA

\begin{abstract}
Recent research in psychology suggest that altruism and altruistic decisions may, in fact, be endogenous and depend on the social situation in which people find themselves. People are more likely to be altruistic, to give to charities and others in need, when they feel secure and safe. This paper looks at the implications of a person's perceived state of security on giving now that there are terrorist threats in the U.S. We use data from the Center on Philanthropy Panel Study (COPPS), and the Panel Study of Income Dynamics (the PSID) to test for endogenous changes in giving and volunteering from before and after the 2001 terrorist attacks. We find evidence indicating that increasing uncertainty resulted in a decline in the giving of both money and time, holding other variables constant, but the relationship is not significant.
\end{abstract}

Keywords: Altruism; Giving and Volunteering; Terrorism

\section{INTRODUCTION}

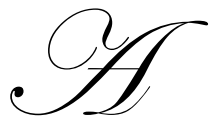

sk almost anyone born before 1990, and it is likely that they can tell you exactly what they were doing the morning of September $11^{\text {th }}$, 2001, when they learned of the terrorist attacks on the U.S. As was true for the bombing of Pearl Harbor and the Assassination of President Kennedy for our predecessors, that moment was burned into our memories as we watched the predictable ordinariness of our daily lives disintegrate. We instantly were thrust into a strange new world of color-coded terror alerts, in which even the shoes of the person sharing an arm rest on a flight to visit relatives could not be trusted. How did people in the U.S. react to this new world of increased uncertainty? We ask whether we can find evidence of any significant effect of these attacks on the giving and volunteering patterns of citizens of the U.S.

Within days of the attacks, the flags came out. Flags showed up in people's hands, on bumper stickers, out windows of cars and on lapel pins as a wave of patriotism the likes of which had not been seen, some said, since World War II, swept the country. People felt the pain of their fellow citizens as the tragedies unfolded, and some lined up to donate blood. Did this sense of unity and mutual concern also lead to a general increase in altruism, a structural change in how people viewed their neighbors, also leading to an increase in the giving of time and money that are the hallmarks of altruistic concern? Or did the new uncertainty lead to a decrease in giving and volunteering in a world in which saving and making plans for tomorrow had become a radical statement of hope?

Recent research in psychology (Mikulincer, et al, 2005 and Miklulincer and Shaver, 2005) has shown that people are more likely to be altruistic, to give to charities and others in need, when they feel secure and safe. Their research suggests that altruism and altruistic decisions may, in fact, be endogenous and depend on the social situation in which people find themselves. In their research, people are found to be more altruistic when they are in situations of more security and when they hold beliefs that the world is basically a safe and good place in which to live. This has important implications on giving and volunteering as the United States continues to face uncertainty in a world of terrorism.

This paper looks at the implications of such a situation on giving now that there are terrorist threats in the U.S. We do this by comparing giving and volunteering in 2001 to that in 2003 . Was there a structural change between these two years, as the country adjusted to the idea of being threatened by terrorists? We begin by running two OLS regressions to determine the significant factors leading to a change in giving. The first of these is for the change in giving of money and the second for the change in the giving of time. 


\section{EMPIRICAL MODEL}

At each time, $t$, person i solves a maximization problem to determine the amount of money or time, $Y_{\text {it }}$ they give. We assume a fixed effects model, in which $\alpha_{\mathrm{i}}$ remains the same for each donor, $\mathrm{i}$, between time periods t. This leads to a giving function for each donor at time $t$.

$\mathrm{Y}_{\mathrm{it}}=\alpha_{\mathrm{i}}+\beta_{1} \mathbf{X}_{\mathrm{it}}+u_{\mathrm{t}} \quad \alpha_{\mathrm{i}}=\Theta+\varepsilon_{\mathrm{i}}$

The fixed effect, $\alpha_{\mathrm{i}}$, therefore subtracts out when comparing two time periods. The difference between the amount given in the two time periods is written as

$\Delta \mathrm{Y}_{\mathrm{it}}=\beta_{1} \Delta \mathbf{X}_{\mathrm{it}}+\eta_{\mathrm{t}} \quad$ Where $\eta_{\mathrm{t}}=\mathrm{u}_{\mathrm{t}}-\mathrm{u}_{\mathrm{t}-1}$

In this paper, one of the variables in the vector $\mathbf{X}$ is the donor's sense of security. We use a dummy variable representing the year after 2001 as a proxy for that variable. The coefficient on the dummy variable for the year after 2001 will represent, in part, a change in donations due to a change in the level of security in our economy.

\section{DATA}

To isolate these changes, we use a data set collected in 2000 and 2002 by the Center on Philanthropy, called the Center on Philanthropy Panel Study (COPPS), which builds upon the often-used Panel Study of Income Dynamics (PSID) by adding questions about giving and volunteering to the demographic questions. We use this to test for endogenous changes in giving and volunteering from before and after the 2001 terrorist attacks. Has the underlying model determining how people in the U.S. give and volunteer changed due to the added underlying uncertainty of the modern world? We do this by using a fixed effects model to test for the difference between two cross-sectional models in the years 2001 and 2003.

\section{VARIABLES}

To examine the determinants of the change in giving between these two years, we calculate the change in both giving and volunteering between the two years. We then seek to determine which variables are influencing these changes by calculating the change in other variables, and running a fixed effects model for the change in both giving and volunteering. The following variables are used as exogenous variables to explain how such giving has changed in this time frame.

\section{Change in Money and change in Time}

Intercept: While not a variable in the traditional sense, the change in intercepts will capture any exogenous change in the giving functions between the two years. The model from psychology will therefore expect this to be negative, as the increased uncertainty will lead to a decline in the giving of both money and time, holding other variables constant.

Change in experience: This variable measures the change in employment experience gained by each observation between the two years studied. As experience is generally positively related to the giving of money, we expect this variable to be positively related to the change in money donated. However, for the giving of time, we expect this variable to be negative, because the opportunity cost of the volunteer has most likely increased as their income increased as they gained experience.

Change in experience squared: This variable measures how a change in experience affects the giving of money. It is likely that the effects of an increase in experience will decline as the change in experience increases, showing a concave pattern. We therefore expect this variable to have a negative effect on donations of money. For donations of time, the coefficient on the square of the change in experience is indeterminate. Previous research has shown that there are human capital investment opportunities in volunteering and that more experience leads to more giving, but at a declining rate (Menchik and Weisbrod 1987; Brown and Landford 1992). A more experienced worker may feel 
that they have more to offer as a volunteer, while a less experienced worker may be volunteering to acquire more human capital.

Change in the number of young people in the household: This variable represents the change in the number of children in the household being studied. Since more children will lead to greater financial responsibilities in the home, we expect this variable to have a negative effect on the giving of money. However, while this may also be true for donations of time, it may alternatively have a positive effect on the giving of time, since people with children are more invested in their communities and more likely to become involved in organizations that use volunteers.

Change in Health: A decline in health will lead to greater financial stress, and therefore to a tendency to give less money. We therefore expect this variable to be negative. We expect a decline in health to be associated with a decline in volunteering, as people who have health problems will have less time to donate.

Change in Income: Previous research has shown that income is positively related to the amount of money donations given (Preston 1988, 1989; Leete 1994). We therefore expect that any increase in income will be reflected by an increase in the giving of money donations. For time, we expect that an increase in income to lead to an increase in donations. Again, this occurs because the constraints faced by the volunteer have been relaxed, and they now have the opportunity to pursue activities beyond that of earning more income.

Change in Wealth: In a manner similar to income, the effect of wealth is expected to have a positive effect on the giving of money donations. We also expect this for donations of time, as an increase in wealth again relaxes the budget constraint of the donor, freeing them up to volunteer more.

Change in employment status: A loss of jobs will lead to less discretionary income and therefore a decline in the amount of money given. Alternatively, acquiring a job when one was unemployed gives one more discretionary income, and thus would be expected to increase the amount of money given. These two imply that the coefficient will be positive on this variable for the giving of money. The human capital model of volunteering, however, suggests that a loss of a job will lead the donor to volunteer more, in an attempt to gain access to the labor market.

Change in retirement status: In a manner similar to that of employment status, a movement from non-retirement status to retired will be expected to lead to a decline in the giving of money. While health concerns that may lead to retirement may make it more difficult to volunteer, at the same time retirement also relaxes the time constraint felt by more healthy donors. It is therefore possible that the amount of volunteer time given will increase as one's status changes form employed to retired. This is supported by the volunteer groups, such as "Retired Senior Volunteer Program" (R.S.V.P.) that encourage retired persons to volunteer their specialized skills.

Table 1: Variable Definitions and Descriptive Statistics

\begin{tabular}{|l|c|c|l|}
\hline \multicolumn{1}{|c|}{ Variable } & Mean & $\begin{array}{c}\text { Standard } \\
\text { Deviation }\end{array}$ & \multicolumn{1}{c|}{ Variable Definition } \\
\hline CHANGEMONEY & -55.32 & 6054.8 & Change in money donation between 2001 and 2003 \\
\hline CHANGETIME & 6.5119 & 275.13 & Change in time donation between 2001 and 2003 \\
\hline CHANGEEXPER & 0.9693 & 22.14 & Change in experience between 2001 and 2003 \\
\hline CHANGEEXPERSQ & 69.196 & 1787 & Change in experience squared between 2001 and 2003 \\
\hline CHANGEYOUNG & -0.1166 & 7.059 & Change in youth between 2001 and 2003 \\
\hline CHANGEHEALTH & -0.0013 & 0.513 & Change in health status between 2001 and 2003. \\
\hline CHANGEINCOME & -2.827 & 108.06 & Change in income between 2001 and 2003 \\
\hline CHANGEWEALTH & 12.95 & 1116 & Change in wealth between 2001 and 2003 \\
\hline CHANGEEMPLOY & -0.006 & 0.609 & Change in percentage employed between 2001 and 2003 \\
\hline CHANGERETIRE & -0.008 & 0.449 & Change in percent retired between 2001 and 2003. \\
\hline
\end{tabular}


Table 2: Determinants of Changemoney and Changetime Donations

\begin{tabular}{|c|c|c|c|c|c|c|}
\hline \multirow[b]{2}{*}{ Variable } & \multicolumn{3}{|c|}{ Model 1 -Changemoney } & \multicolumn{3}{|c|}{ Model 2- Changetime } \\
\hline & Coefficient & $\begin{array}{c}\text { Standard } \\
\text { Error }\end{array}$ & T-ratio & Coefficient & $\begin{array}{c}\text { Standard } \\
\text { Error }\end{array}$ & T-ratio \\
\hline INTERCEPT & -68.43 & 79.708 & -0.86 & -1.3078 & 4.7213 & -0.28 \\
\hline CHANGEEXPER & 13.983 & 14.436 & 0.97 & 2.7019 & 0.9036 & $2.99 *$ \\
\hline CHANGEEXPERSQ & -0.037 & 0.1901 & -0.20 & 0.0294 & 0.0122 & $-2.40 * *$ \\
\hline CHANGEYOUNG & 2.1929 & 11.691 & 0.19 & 1.7346 & 0.6712 & $2.58^{*}$ \\
\hline CHANGEHEALTH & -127.8 & 166.07 & -0.77 & 27.769 & 10.186 & $2.73^{*}$ \\
\hline CHANGEINCOME & 5.8721 & 0.7984 & $7.35 *$ & 0.0849 & 0.0417 & $2.04 * *$ \\
\hline CHANGEWEALTH & 0.3241 & 0.0753 & $4.30 *$ & 0.0114 & 0.0041 & $2.73^{*}$ \\
\hline CHANGEEMPLOY & 92.080 & 173.49 & 0.53 & -1.126 & 11.022 & -0.10 \\
\hline CHANGERETIRE & -213.38 & 263.57 & -0.81 & 22.72 & 16.373 & 1.39 \\
\hline \multirow{3}{*}{\multicolumn{4}{|c|}{$\begin{array}{l}\text { F-Value } \\
\text { R-squared } \\
\text { Number of observations }\end{array}$}} & \multicolumn{3}{|c|}{$7.19 *$} \\
\hline & & & & \multicolumn{3}{|c|}{0.016} \\
\hline & & & & & 3540 & \\
\hline
\end{tabular}

Stars indicate significant at the $0.01(*), 0.05(* *)$ and $0.10(* * *)$ critical levels

\section{RESULT AND DISCUSSION}

Table 1 provides summary statistics and descriptions for the variables. According to the results in this table, between 2001 and 2003 the mean change in money donation decline by -55.32 , while the mean change in time donation increase by 6.5119. On average, donations from experience donors increase at an increasing rate. During the period the average number of young people in donors household, the health status of donors, and the income of donors declined. There was a mean increase in donors wealth (12.95) but the average percentage of donors employed and retired decline by $(-0.006$ and -0.008$)$ respectively.

The regression results in Table 2 presents factors determining the change in the giving of money and time donations between 2001 and 2003. However, based on our theoretical specification and empirical interest our point of focus is on the intercept coefficients. As predicted by the work of the psychologists (Mikulincer, et al, 2005 and Miklulincer and Shaver, 2005), the intercept term is negative in the case of both time and money. It is, however, not significant in either case. This may be due to the fact that the terrorist attacks encouraged people to change the mix of their donations, rather than simply decrease them. For example, more people may be giving to organizations such as the police and fire and military which they perceive are more directly involved in providing security, while giving less to organizations such as the American Cancer Society that are not involved in providing security.

The regression results in Table 2 indicate that both models are statistically significant, but overall the models do not explain much of the variation in the dependent variables. For the giving of money and time, the coefficients on the variables change in experience and experience squared indicate a concave relationship between the change in experience and the amount of money and time donated. This implies that as experience increases, donations increase, but at a decreasing rate. These coefficients are statistically significant for donations of time, but not for money. The change in the number of children in a household is positively related to the change in the giving of both time and money. However, it is only statistically significant for the effect of this change on the change in donations of time. A change in the health status of the donor is negatively related to donations of money, but not significant. Alternatively, it is positively and significantly related to a change in donations of time. A change in income is positively and significantly related to changes in donations of both time and money, as expected. Similarly, a change in wealth is also positively and significantly related to changes in donations of both time and money. The effects of the changes in employment and retirement status on donations of time and money have the expected signs but are not statistically significant. The insignificance of these variables on the changes in donations of time may reflect conflicting possible models of volunteer labor, those involving leisure seeking activities and those involving human capital investment, both of which may be operating at the same time, but for different donors. 


\section{CONCLUSION}

The research from psychology that motivated this research would predict a negative and significant sign on the intercept term for the fixed effect model. While our regressions found a negative sign, they did not indicate a statistically significant change between the two years. This may be due to a variety of reasons, including the possible redistribution of organization receiving donations. In addition, the limited time period may not completely reflect structural changes that occurred between the two years studied. We did, however, find expected results for the effects of the changes of some variables, such as income and wealth on the giving of time and money, which were significant in both cases. In addition, experience, number of children, and health were all statistically significant in explaining change in donations of time. It appears that the changes in the variables studied have a stronger impact in determining the change in time donations between these two years, as the country worked to find a "new normal" after the terrorist attacks.

\section{AUTHOR INFORMATION}

Walter O. Simmons is Professor and Chair in the Department of Economics and Finance, in the Boler School of Business, John Carroll University. He received his Ph. D in Economics from Wayne State University, in Detroit Michigan and his undergraduate degree from Oakwood College, in Huntsville Alabama. His research interests include international financial centers, labor market discrimination, economics of health care, and the economics of the non-profit sector. E-mail: wsimmons@jcu.edu. Corresponding author.

Rosemarie Emanuele is Professor of Mathematics and Chair of the Mathematics department at Ursuline College. She received her Ph.D. in economics from Boston College. Her research has concentrated on the economics of the nonprofit sector, including the markets for paid and volunteer labor in this sector. E-mail: remanuel@ursuline.edu.

\section{REFERENCES}

1. Brown, Eleanor and Lankford, H. (1992) "Gifts of Money and Gifts of Time: Estimating the Effects of Tax Prices and Available Time", Journal of Public Economics 47, pp. 321-341.

2. Leete, Laura. (1994) "Nonprofit Wage differentials in the United States: New Estimates from the 1990 Census" Working Paper, Mandel Center for Nonprofit Organizations Discussion Paper Series.

3. Menchick, Paul and B. Weisbrod. (1987) “The Supply of Volunteer Labor" Journal of Public Economics, 32, pp. 153-183.

4. Mikulincer, M., \& Shaver, P. R. (2005) Attachment security, compassion, and altruism. Current Directions in Psychological Science, 14, 34-38.

5. Preston, Anne E. (1988) (b) "The Nonprofit Firm: A Potential Solution to Inherent Market Failures" Economic Inquiry vol. 26, 493-506.

6. Preston, Ann E. (1989) "The Nonprofit Worker in a for-Profit World” Journal of Labor Economics 17:438463. 
NOTES 